\title{
Book Review: Agricultural Systems for the 21st Century - Global Agriculture Developments
}

\author{
Nicholas E. Korres ${ }^{1}$ \\ ${ }^{1}$ Department of Crop, Soil and Environmental Sciences, University of Arkansas, AR, USA \\ Correspondence: Nicholas E. Korres, 1366 W. Altheimer Drive, Department of Crop, Soil and Environmental \\ Sciences, University of Arkansas, AR 72704, USA. E-mail: nkorres@yahoo.co.uk; korres@uark.edu
}

Online Published: May 15, 2015 doi:10.5539/jas.v7n6p233 URL: http://dx.doi.org/10.5539/jas.v7n6p233

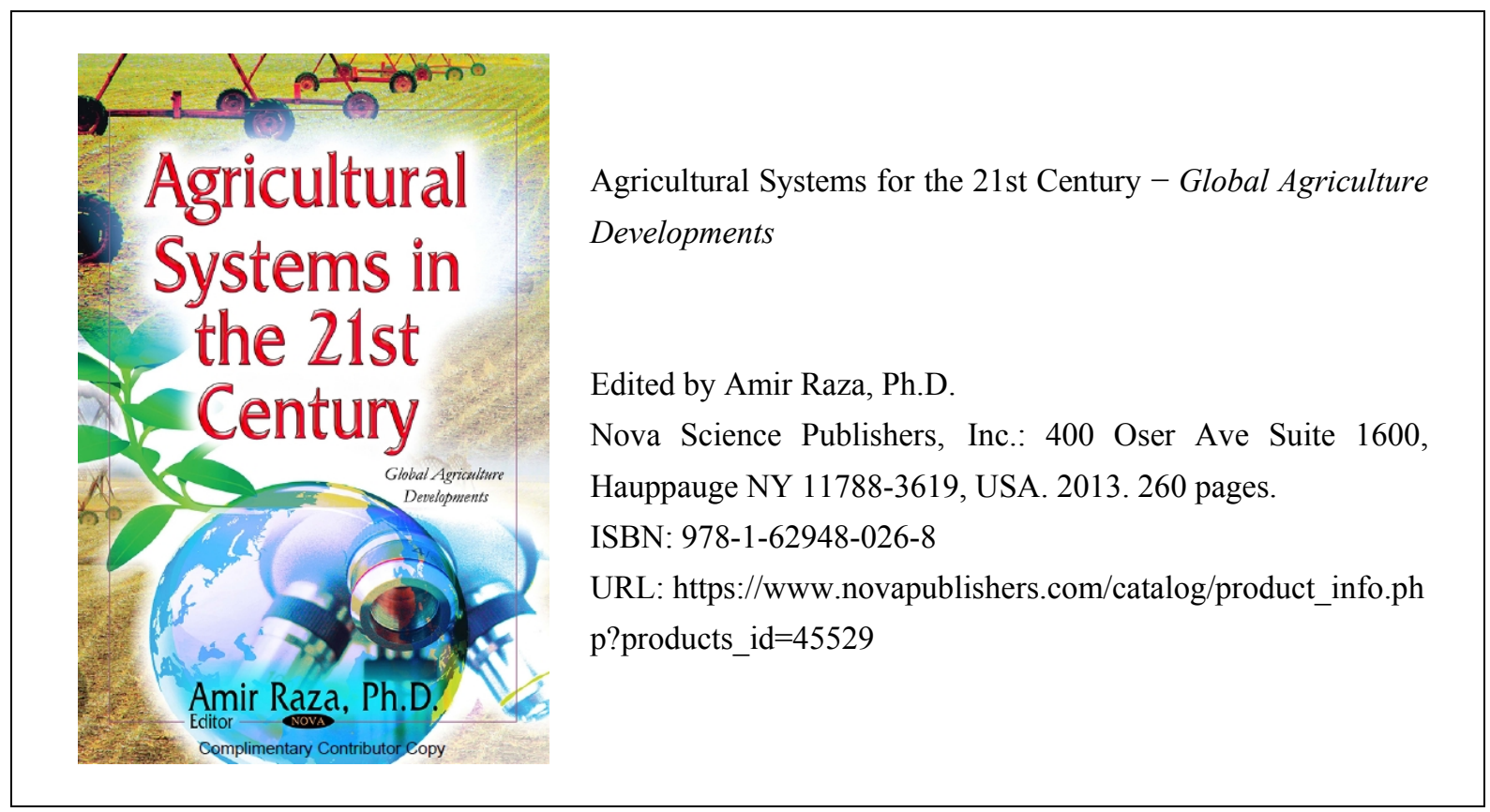

\section{Summary of Review and Endorsements}

Agriculture, nowadays, is challenged in many ways for sustainable food production particularly under current climate change scenery, the consequences of which we are experiencing even in our daily activities.

There is an increasing concern on agricultural practices and potential food production given the increase of human population but also resource limitations mainly owned to water availability and quality, crop nourishment and crop protections costs.

So, I have dipped into this book at random and also to answer specific queries. I found this book a useful source of supplementary information to the existing literature as it covers, in depth, many important disciplines either as extended literature-based case studies or as global issues with great scientific, social and environmental importance.

\section{Body of the Review}

The impact of landscape agriculture in erosion prone regions; rice farming and integrated weed control or the application of biotechnology for sugarcane improvements, address important issues where agriculture holds a significant role. These chapters serve as case studies at national scale and provide insights in a comprenhesive manner. 
Representative chapters such these dealing with water scarcity; sustainable agriculture or the impact of desertification and population density on food security address the necessity to rethink our practices on how we use resources for our food production.

The importance of international agricultural research and strategies for developing international collaborations but also the importance of the private and governmental partnerships on rural development is clearly covered by this book.

Finally, references on sustainable viticulture but also on the importance of micronutrients for healthy crops and humans can be considered as added value information.

Chapter one uses wheat as a model crop and presents some strategies as a mean for yield enhancement and increased water use efficincy and water availability through water treatment technologies and bio-remediation.

Developing international collaborations, as the globalization in science and innovation is progressing rapidly, is an important element for addressing evolving challenges such as health issues of humans and animals, climate change, food security or resources depletion.

Chapter two outlines key strategies for developing international collaborations for the development of sustainable agricultural systems particularly in emerging economies. The nature of international collaborations and key agencies that may provide funding for international collaborative research are outlined in this chapter.

The degradation of the natural resources through erosion and the role of landscape agricultural systems in controlling landscape deterioration is explained in chapter three.

The interelationship between technology and scince for the development of sustainable agricultural systems is described in chapter four. The current situation regarding food security through the development of sustainable agriculture in the context of climat change effects on biodiversity, farmer education, water management, renewables are holistically discussed.

Yield improvements and the need for integrated weed management in rice farming systems in Philippines are clearly described in chapter five.

Another interesting topic this book deals with is the use of micronutrients for soil and human health improvements in chapter six. Here the authors discuss, in a comprehensive manner, the role and function of micronutrients in plants and in human and animal health. Also the requirements of human, animal and plant for micronutrients are highlighted in detail. They also discuss about soil factors causing micronutrient deficiencies whereas zinc deficiency attracts the attention of the reader as the authors make an extensive reference on the role of zinc deficiency on human health and suggest approaches to overcome it. Agronomic and plant nutrition approaches to enhance the micronutrient content of food crops and genotypic variation in uptake and accumulation of micronutrients are presented.

Chapter seven explains how the employment of biotechnology can contribute towards the development of new sugarcane cultivars which are resistant to biotic and abiotic stresses hence increase the potential of this crop as food and feedstock for renewable energy production.

The chance for private international investment opportunities within the sub-Saharan agricultural region under current notable agricultural, environmental, economic and social challenges is highlighted in chapter eight.

Chapter nine discusses the efforts for improvement of grape varieties quality through efficient use of non-renewable natural resources. Knowing the specificities of each region in terms of environmental factors and agricultural practices is crucial for the development of sustainable viticulture. The development of multivariate models combining factors that affect the yielding ability of a vine variety, within a geographic region, can be proved very promising for sustainable viticulture production.

Another important issue that threatens food security, as discussed in chapter ten, is that of desertification and human population density increases. Increases in population density results in decreases of agricultural, industrial and medical resources which are followed by economical, geographical, and biological losses. This chapter clarifies the scientific findings that can be used for long-term economic and social planning against desertification.

To summarize, this reviewer believes that this book is a useful source of supplementary information for scholars in agriculture and related disciplines but also for policy decision makers and extension services professionals. 


\section{About the Book Editors and Authors}

Editors:

Amir Raza is a senior scientist working at Nuclear Institute for Food and Agriculture (NIFA), Peshawar, Pakistan. He has a PhD in Natural Resources and Life Sciences and over 12 years experience in the field of agriculture, research and development. He is also a member of International Society of Root Research and approved supervisor for doctoral students in agricultural sciences - Higher Education Commission (HEC), Government of Pakistan.

Authors:

Chapter 1: Zeshan Ali is working at the National Institute of Bioremendation, National Agricultural Research Centre, Pakistan.

Chapter 2: Prof Mehmet Cakir is working at the Western Australian State Agricultural Biotechnology Centre with expertise in agronomy and molecular technologies applicable to drought selection.

Chapter 3: Professor Ekaterina G. Kotlyarova holds the Chair of Agriculture and Agrochemistry, Agronomy Department at Belgorod State Agricultural Academy named after V. Ya. Gorin, Rusia.

Chapter 4: Professor Alvina G. Kazi at the Atta-ur-Rahman School of Applied Biosciences, National University of Sciences and Technology, Pakistan employs cytogenetics, molecular genetics, physiology, pathology, pre-breeding and breeding to develop elite wheat varieties with multiple disease resistance and stress tolerance.

Chapter 5: Jesusa C. Beltran carries her PhD research at the Philippine Rice Research Institute, Philippines and at the School of Agricultural and Resource Economics, Faculty of Natural and Agricultural Sciences, The University of Western Australia. Her research focuses on the economic analysis of weed management options in the rice production in the Philippines.

Chapter 6: Dr. Muhammad Imtiaz is a Principal scientist, at the Soil Science Division, Nuclear Institute for Food and Agriculture, Pakistan. His research interests focused on plant nutrition with specific reference to micronutrients.

Chapter 7: Dr. Saboohi Raza is working at the Agricultural Biotechnology Group, at Nuclear Institute of Agriculture, Pakistan. His research interests include biotechology, molecular biology, somaclonal variation and plant tissue culture.

Chapter 8: Dr. Mark P. McHenry researchers various new technology developments in the School of Engineering and Energy within Murdoch University's Faculty of Minerals and Energy. Mark has published several peer-reviewed journal articles, book chapters, and reports on renewable energy resources and technologies, carbon biosequestration, power systems, bioenergy conversion technologies, soil organic carbon and biochar developments, energy policy, and agricultural mitigation and adaptation to climate change.

Chapter 9: Silvia Petronilho is working in QOPNA, Departamento de Quimica, Universidade de Aveiro, Portugal.

Chapter 10: Adeena Shafique holds a degree, in applied biosciences and works at the Atta-ur-Rahman School of Applied Biosciences, National University of Sciences and Technology, Pakistan.

\section{Copyrights}

Copyright for this article is retained by the author(s), with first publication rights granted to the journal.

This is an open-access article distributed under the terms and conditions of the Creative Commons Attribution license (http://creativecommons.org/licenses/by/3.0/). 